\title{
Students' Perceived Challenges of Attending a Flipped EFL Classroom in Viet Nam
}

\author{
Nguyen Huu Anh Vuong \\ Faculty of Psychology and Education, Universiti Malaysia Sabah, Sabah, Malaysia \\ Choon Keong Tan \\ Faculty of Psychology and Education, Universiti Malaysia Sabah, Sabah, Malaysia
}

Kean Wah Lee

Faculty of Arts and Social Sciences, The University of Nottingham Malaysia Campus, Malaysia

\begin{abstract}
Flipped classroom is gaining more and more popularity among educators and researchers all over the world; however, its implementation in Viet Nam is still in infancy. This small-scale research project attempts to investigate students' perceived challenges when attending a flipped English grammar class. Qualitative research design was adopted to address the research question. The participants include 34 secondyear students majoring in the English language at a state university in Viet Nam. The instruments consist of an open-ended questionnaire and semi-structured interviews. Thematic analysis was employed to address the qualitative data. The findings highlight that Vietnamese students encounter several challenges when attending the flipped classroom including difficulty in self-regulated learning, heavy learning workload, lack of immediate support and lack of ICT resources. Accordingly, the present research has some pedagogical implications to help address those obstacles for successful implementation of this innovative teaching mode in the Vietnamese EFL context.
\end{abstract}

Index Terms - flipped classroom, EFL, challenges, Viet Nam

\section{INTRODUCTION}

The advance and prevalence of modern technology has affected every facet of people's lives and led to the dramatic changes in all areas including education. The traditional instructional methods which used to be dominant in the past have become outdated and the new and innovative ways of teaching have been introduced to cater for diverse needs and abilities of "digital natives" (Prensky, 2001) - a new generation of students who are born in the digital age and are entirely familiar with computers, smartphones and the Internet.

In the past decade, flipped classroom, a new pedagogical model originated in the United States of America, has gained much attention among educators from all levels and fields and become a growing teaching trend in the world (Mehring, 2017). In the flipped classroom, the lectures are moved out of the face-to-face class meetings to free up inclass time for deeper critical and active learning activities (Stone, 2012). This method has demonstrated its effectiveness in various disciplines with regards to improving students' achievement, performance, engagement, etc. and offers a variety of benefits to both teachers and students (Lopes \& Soares, 2018). In addition, it is mostly reported that both teachers and students have positive perceptions towards this innovative approach (El-Bassuony, 2016).

Viet Nam, in recent years, has been trying to boost the English language education. In order to achieve that goal, new instructional methods are encouraged to improve the current English learning and teaching situation. In that trend, the flipped classroom model started to be mentioned in the mass media and has been implemented by some teachers in EFL classes (Bui, 2016; Nguyen, 2014; T. N. Tran, 2016; T. T. Q. Tran, 2017). Although studies on flipped classroom in the Vietnamese EFL teaching and learning context are in their early stage, it is reported that this pedagogical method may become a potential teaching method. Since flipped classroom is quite a new teaching mode in Viet Nam, students may encounter some challenges and difficulties when participating in such classes. Thus, this research aims at investigating the challenges that students may face when attending a flipped class. The following research question guided the current study: What challenges do students encounter when attending a flipped English grammar classroom?

\section{LITERATURE REVIEW}

\section{A. Flipped Classroom}

Over the past decade, flipped classroom, as a form of blended learning, has appeared as an innovative teaching method which attracts much attention from teachers and researchers over the world. The teaching model was first introduced by a professor at Cedarville University in Ohio, Dr. J. Wesley Baker when he put the PowerPoint slides on the university's computer network and asked his students to read them before coming to class. The whole class time 
was mostly devoted to the application and practice of the new concepts that the students acquired beforehand through collaborative activities. The new instructional model is illustrated in Fig. 1 Baker (2000) then discovered that his students had learned a great deal through this teaching approach.

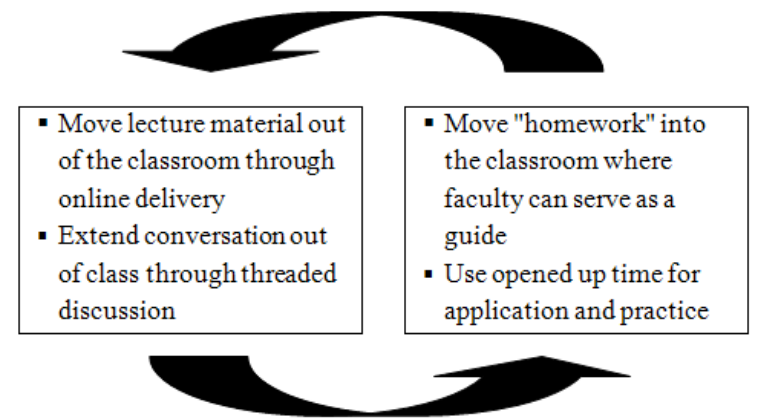

Figure 1. The Flipped Classroom Model (Baker, 2000)

Due to the rapid advance of information and communication technologies in recent years, flipped classroom has become a growing trend in education. According to Bishop and Verleger (2013), the teaching model is defined as "a new pedagogical method, which employs asynchronous video lectures and practice problems as homework, and active, group-based problem-solving activities in the classroom" (p .1). More specifically, flipped classroom gives students the opportunity to learn new contents at home before coming to class through online educational materials such as videos, podcasts or presentation slides. Students can watch the digital lessons as many times as needed to fully prepare for their face-to-face class sessions. The classroom time will then be maximized for active learning activities to apply and practice the newly-acquired knowledge at a richer and deeper scope. This teaching model, grounded in the learning theory of constructivism and active learning, helps transform the learning environment from teacher-centered to student-centered. As such, students can take control of their own learning while teachers work as facilitators to monitor, support and give feedback to their students instead of knowledge providers in traditional classes (Strayer, 2012). Besides, technology is an essential aspect of flipped classroom as it enables teachers to offer learning content in different formats, deliver digital lectures, create online activities, monitor students' progress and involvement, assess their achievement, etc. (Bishop \& Verleger, 2013).

There have not been any fixed guidelines for exactly what a flipped classroom should look like so far. Albert \& Beatty (2014) pointed out that flipped classroom possesses five following major characteristics: (a) educational process transforms students from passive to active learners; (b) technology facilitates the approach; (c) class time and traditional homework time are inverted so that homework is done first; (d) content is given in real-world context; and (e) class activities engage students in higher order of critical thinking and problem solving or help them grasp particularly challenging concepts.

\section{B. Benefits of Flipped Classroom}

Flipped classroom is reported by many researchers to be highly beneficial for students of different disciplines. The benefits include more efficient use of classroom time for active learning activities, the improvement of students' learning outcomes and achievement, increased teacher-student and student-student interactions during class meetings, the promotion of the student-centric learning environment, and the address of multiple learning styles. In addition, the flipped classroom approach enables students to learn anytime, anywhere and at their own pace, access course materials continuously, personalize their learning process, advance their learning engagement and ownership, develop their reflective abilities and generic skills, improve their self-discipline and self-regulation skills, promote their learning autonomy, etc. (He, Holton, Farkas, \& Warschauer, 2016; Yang, 2017). The majority of research studies indicate that both teachers and students have a positive and favorable attitude towards this innovative instructional model (Doman $\&$ Webb, 2015). In comparison with some other existing pedagogical models, this approach offers numerous benefits which are extremely appealing to administrators, educators, students, and parents.

\section{Challenges of Flipped Classroom Implementation}

Despite numerous benefits, it is identified that students encounter some challenges when attending the flipped classes. Missildine et al. (2013) pointed out that the increased amount of out-of-class preparation time may negatively influence students' satisfaction levels. The heavy workload of pre-class activities may overwhelm students' time at home. Similar findings made by Strayer (2009) indicate that the students' new roles in the flipped classroom give them a much higher demand. They may feel more pressure to complete the pre-class activities, and therefore become uncomfortable with the in-class practices. As such, the flipped classroom would not be effective at all.

According to some researchers such as Chen (2016) and Simpson and Richards (2015), one big challenge is related to students' resistance to a totally new teaching mode. Students have become familiar with traditional lecture methods and find it initially struggled to adjust to an innovative teaching style with new routines, responsibilities and expectations. 
Milman (2012) indicated that students may not view the full lesson videos or may not fully comprehend the video contents and therefore be unprepared for the learning activities during class meetings or difficult to keep pace with their classmates. Besides, she added that the conditions under which they watch the videos may not be the best for learning new concepts. Students have to be responsible for their own learning but the fact that there are many distractions with the online session of the flipped class may lead to the lack of concentration. Students often get distracted by other websites or social networks and the surroundings, which make them unable to fully focus on watching the video lessons. In another study, Lopes \& Soares (2018) mentioned such challenges that students might face as their attendance fluctuation, some lack of a responsible attitude towards knowledge construction, some difficulty in coping with the continuous leaning pressure in the before-class session. Also, Bhagat et al. (2016) included lack of instant help or outof-class supports as one other challenge. Some students lament that they cannot ask their questions immediately during pre-class activities. Lo \& Hew (2017) categorized the above-mentioned challenges as student-related ones.

Since the flipped classroom approach heavily relies on homework and technology use, Missildine et al. (2013) identify several operational challenges related to infrastructure, classroom availability and limited high-speed Internet access. Some students might not have Internet access at home while others might have no laptops or mobile devices to view the digital lessons.

The aforementioned challenges in the flipped classroom implementation process are all reported in study fields excluding foreign language education, especially in the Vietnamese context.

\section{Previous Studies on Flipped EFL Classes}

With regards to EFL education, although research reports on flipped EFL classrooms are not abundant in the literature (Hung, 2015; Webb \& Doman, 2016), this instructional model demonstrates its potential effectiveness and success in teaching language knowledge and language skills.

Hung (2015), a pioneer in applying flipped classroom in EFL teaching context, found that both teachers and students have positive perceptions and favorable attitudes towards this pedagogical approach. His research also revealed that flipped classroom helps improve students' academic performance in general. Several other researchers (e.g. Başal, 2015; Engin, 2014) echo his findings when concluding that the approach has positive impacts on students' performance and proficiency levels in different EFL areas.

According to Al-Harbi \& Alshumaimeri (2016), flipped classroom helps tackle some common problems of English language learners including lack of participation, communication and interaction opportunities, lack of sufficient feedback, low proficiency levels, etc. Additionally, this instructional model maximizes the in-class time for communicative activities.

Within the Vietnamese EFL context, although studies related to the flipped classroom approach are still limited, some authors such as Bui (2016), Nguyen (2014), T. N. Tran (2016) and T. T. Q. Tran (2017) started to discuss the potential adoption of the flipped classroom approach. As reported by these researchers, this teaching mode can be a promising instructional method in EFL education, especially in addressing the issues related to the local teaching context. The approach proves to be effective in improving students' academic achievement and gets positive feedback from them. However, no empirical studies on the challenges of flipped classroom have been found in the existing literature. Therefore, it is hoped that the findings of the current study will make a modest contribution to the successful implementation of the flipped classroom approach in the Vietnamese EFL teaching and learning context.

\section{METHODOLOGY}

\section{A. Research Design}

Unlike the quantitative approach, qualitative research helps explore and interpret the meanings of socio-cultural, economic and political issues and challenges (Creswell, 2009). Therefore, the current study was based on a qualitative research design to address the research question. Thematic analysis was employed to identify the themes related to the challenges students faced.

\section{B. Participants}

The participants included 34 second-year students, majoring in the English language at University of Foreign Language Studies, the University of Da Nang, a state university in Viet Nam. They were enrolled in the course of English Integrated Skill B2.4 which included four language skills and grammar knowledge in the second semester of 2018. Most of them are female, aged between 19 and 21, which reflects the normal ratio of male and female students majoring in foreign language studies in Viet Nam. Their English language proficiency is considered at the lowerintermediate level.

\section{Instruments}

Qualitative data were collected to address the research question. To identify the students' perceived challenges in a flipped classroom, a questionnaire containing open-ended questions was administered to all participants in which students were asked to give responses about the challenges they encountered in the flipped class. Besides, a semistructured interview with guiding questions and prompts developed beforehand was conducted with 10 participants 
selected from the class to obtain in-depth information concerning the challenges. Both of the instruments were piloted before the actual study.

\section{Data Collection and Analysis}

The participants attended a flipped English grammar class in ten weeks as part of the course of English Integrated Skill B2.4 in which there were ten grammatical points to be taught, one point per week. In a weekly flipped class, students were asked to watch a lesson video containing one grammar point before coming to class. The videos created by the instructor were posted on a Moodle e-learning platform for the students to view. Besides, the students had to take a short online quiz after watching the videos to check their understanding of the lesson. During the 50-minute class meeting, after a short review of new grammatical points by the instructor, most of the time was devoted to active learning activities through which the students applied what they had learned at home in communicative practice.

After ten weeks of attending the flipped class, the students were delivered an open-ended questionnaire to complete. Ten out of 34 participants were then randomly selected for the semi-structured interview. All the interviews were audio recorded. The students gave responses to the open-ended questions in the questionnaire and the interviews in Vietnamese since they felt more confident in their first language.

The interview recordings were transcribed verbatim. The responses to the open-ended questions in the questionnaire and the interview transcripts were translated into English. The qualitative data were then coded and analyzed manually. Thematic analysis (Braun \& Clarke, 2006) was adopted to identify the themes with sub-themes related to students' perceived challenges.

\section{FINDINGS AND DiSCUSSION}

As emerged from the qualitative data, there are four core themes which represent the challenges perceived by the students when attending the flipped English grammar class (as illustrated in TABLE 1). Most of the identified challenges are consistent with the findings from previously reviewed studies.

TABLE 1.

VIETNAMESE EFL STUDENTS' PERCEIVED CHALLENGES WHEN ATTENDING A FLIPPED CLASS

\begin{tabular}{|l|l|l|}
\hline No. & Major Themes & Sub-Themes \\
\hline 1 & Difficulty in self-regulated learning & $\begin{array}{l}\text { A) Distracted by social networks and entertaining websites } \\
\text { B) Distracted by the surroundings } \\
\text { C) Forget to do pre-class activities }\end{array}$ \\
\hline 2 & Heavy learning workload & $\begin{array}{l}\text { A) More time devoted } \\
\text { B) More efforts }\end{array}$ \\
\hline 3 & Lack of immediate support & $\begin{array}{l}\text { A) No immediate feedback } \\
\text { B) No immediate responses to queries }\end{array}$ \\
\hline 4 & Lack of ICT resources & $\begin{array}{l}\text { A) Low Internet speed } \\
\text { B) Lack of Internet access at home } \\
\text { C) Lack of laptops or mobile devices }\end{array}$ \\
\hline
\end{tabular}

\section{A. Difficulty in Self-regulated Learning}

Difficulty in self-regulated learning is one major theme deduced from the students' responses in the open-ended questionnaire and the interviews. Since students must acquire the new knowledge ahead of time so as to apply it in more engaging activities, the flipped classroom much depends on the pre-class activities. However, some participants mentioned that they found it difficult to take responsibility for their own learning at home because of many distractions which may cause them to lose concentration. As two students explained:

"I faced the challenge regarding concentration. While I was viewing the lesson videos, it was hard to keep me away from other things like using Facebook, watching online football matches or listening to music. So, I couldn't totally understand and concentrate on the lessons. When I studied in coffee shops, the people surrounding me sometimes made noise and broke my concentration."

"I think the biggest challenge for me is associated with self-regulated learning. In order to achieve success in the flipped classroom, I must be seriously studious. But sometimes I felt lazy, I didn't want to do online activities. In addition, there were numerous websites and social networks that distracted me while I was learning on the e-learning platform."

Besides, remembering to do weekly out-of-class activities is not an easy task. One student confessed in the interview:

"This approach requires students to take high responsibility for their own learning. But sometimes, I forgot to do the pre-class activities."

Students then may not view or fully understand the instructional videos and therefore be insufficiently prepared for active learning activities during class time. This is consistent with the findings of Milman (2012) in that it is hard to control the students' learning at home. Similarly, Chao et al. (2015) indicated "it is difficult to ensure that students had truly previewed the video" (p. 524)."

\section{B. Heavy Learning Workload}


Another noticeable challenge which many students mentioned is heavy learning workload. The flipped classroom model requires students to do out-of-class activities such as watching instructional videos and doing online quizzes before coming to class. Hence, the students voiced that they had to work more in the flipped classroom. Also, they had to devote more time to the course at home. For example, one student complained in the interview:

"It occupied me a lot of time compared to the traditional classes. In the past, I didn't have to do anything before class meetings. But now, you know, I must spend time on a lot of homework including watching the videos, doing the quizzes..."

Interestingly, two students revealed the reasons why it took them much time at home with the flipped class:

"I was frequently attracted by other entertaining websites or social networks like Facebook during my online learning. And, of course, I had to take much more time to fully understand the online lessons and complete the quizzes."

"Sometimes, low Internet connection hindered me from doing pre-class activities. Well, it was quite time-consuming to load the lesson videos to watch with the low Internet speed."

Many studies in the literature (e.g. Missildine et al., 2013; Strayer, 2009) support this result when indicating that students must devote more preparation time to pre-class activities; and consequently learning in flipped classes is more demanding than in traditional ones.

\section{Lack of Immediate Support}

One further challenge that students perceived in the flipped classroom is associated with the timely support and feedback from their teachers. In order to effectively participate in a flipped class, students had to watch the video lessons at home as a preparation for their class meetings without their teachers' help. Students then complained that when watching the digital lessons, if they had any queries regarding the content, they could not ask their teacher immediately as in traditional lectured classes. The challenge is detailed in the following comment from an interviewee:

"I couldn't talk immediately to my teacher when I had any query about the video lessons. It's a challenge for me."

Two other students expressed similar ideas:

"Sometimes, I didn't fully understand one grammatical point when watching the lesson videos or doing the quizzes. I couldn't get timely feedback from my teacher as I did during the lectures of traditional classes."

"At times, I was unclear of a grammatical point but I couldn't get immediate responses from my teacher, so I had to search Google to tackle the problems."

This challenge is aligned with the report by Bhagat et al. (2016) when he showed that lack of instant help from teachers can be an obstacle for students in a flipped class.

\section{Lack of ICT Resources}

A final common theme of challenges is related to the inadequate ICT resources such as the Internet or mobile devices. ICT technology plays a crucial role in the flipped classroom. Interestingly, no students reported IT illiteracy as a challenge and found difficulty in using the Moodle e-learning platform. The reasons may be that students are now all good at IT skills and the LMS Moodle is easy to use. However, echoing the findings of previous studies by Missildine et al. (2013) and Chen (2016), lack of ICT resources is perceived as a hindrance to the implementation of a flipped classroom. Students have to do all the pre-class activities out of class with the help of ICT technologies, but their conditions are not the same. Some students stated they had no laptop, while others reported the technological issues including no Wifi access and low Internet speed. In the interviews, the participants mentioned this challenge in more details. For example:

"I live in a small rented room. And one challenge I faced is the unavailability of Wifi. I couldn't use my laptop or smartphone to do the online activities in my room. So, I had to go to coffee shops or the university library. It is quite an obstacle for me."

"I sometimes have problems with the Internet access such as disconnection or low speed, which causes many difficulties in attending the flipped class."

Two students talked about the lack of laptops:

"I don't have my own laptop. It's a bit difficult for me to watch the online lectures and do other activities."

"One time, my laptop was broken down and I found it hard to do the online activities. I had to wait for one day to borrow the laptop from my friend."

As can be seen from the research findings, all of the identified challenges are concerned with the pre-class session of the flipped classroom where students have to be responsible for their own learning with the aid of educational technology. It is also interesting to note that the challenge of students' initial resistance to adopt the flipped classroom approach was not mentioned by the students as reported in several studies (e.g. Chen, 2016; Simpson \& Richards, 2015). Probably, the students were well informed of the new pedagogical approach at the beginning of implementation. Once they become perfectly aware of procedures and benefits of the approach, they will be willing to actively participate in the flipped class. Hence, thorough preparation is considered as the key to flipping the classroom successfully and limit the challenges (Adnan, 2017). 
The present study attempted to explore the challenges that obstruct the successful implementation of the flipped classroom approach as perceived by the students. The main identified obstacles are difficulty in self-regulated learning, heavy learning workload, lack of immediate support and lack of ICT resources. If the aforementioned challenges are tackled, flipped classroom will soon become an effective teaching model in the Vietnamese EFL context.

In order for students to deal with such challenges, it is suggested that some measures should be taken by both teachers and students. First of all, pre-class activities, especially the instructional videos, should be kept short enough to avoid distraction, and well planned to make content readily digestible (Adnan, 2017). They should also be created in an interesting way in order to fully gain students' concentration. The design of online quizzes should be strictly stuck to the contents taught in the videos so that students are able to do them once fully watching the videos. Besides, after posting a lesson video or any learning activities on the platform for students to do at home, teachers should send emails and messages to remind them. In the classroom, there should be one or two computers available in case some students forget to view the digital lessons at home to ensure that all students acquire the new knowledge before doing the inclass activities. Next, teachers should design the out-of-class learning activities as short as possible to lessen time burden and ease the heavy workload on students. The instructional videos should be kelp short in length and other activities such as quizzes or forum discussions not too complicated. In this way, students would not be frustrated because of the extra workload (Lo \& Hew, 2017). In addition, an online forum should be open on the e-learning platform for students to post any questions related to the lessons and teachers should try to reply back as soon as possible. Also, students are encouraged to online discuss the lesson contents with their peers. Last but not least, for students who do not have any computers or other devices to do pre-class activities, teachers can work with the university to offer them those resources in the library and computer rooms or even equip the classroom with some computers for their own use. In some cases, students are suggested to share with their friends. The online platform should be designed for all different kinds of computing devices to be able to access. Students are encouraged to go to the university library or public places where the Internet is available.

This study still has some limitations due to the fact that it was conducted with a small group of participants from only one university in Viet Nam. Additionally, the research was merely based on the qualitative data, which lacks the triangulation from other data resources. Given the small sample size, the generalization is limited. Nevertheless, the research findings can serve as a valuable reference for teachers when implementing this innovative approach in EFL classes. Further research using different types of data and involving a larger sample size need to be carried out to shed more lights on the issue in the future.

\section{REFERENCES}

[1] Adnan, M. (2017). Perceptions of senior-year ELT students for flipped classroom: A materials development course. Computer Assisted Language Learning, 30(3-4), 2017.

[2] Al-Harbi, S. S., \& Alshumaimeri, Y. A. (2016). The flipped classroom impact in grammar class on EFL Saudi secondary school students' performances and attitudes. English Language Teaching, 9(10), 60-80.

[3] Albert, M., \& Beatty, B. J. (2014). Flipping the classroom applications to curriculum redesign for an introduction to management course: Impact on grades. Journal of Education for Business, 89(8), 419-424.

[4] Baker, J. W. (2000). The "Classroom Flip": Using web course management tools to become the guide by the side. In J. A. Chambers (Ed.), Proceedings of the 11 th International Conference on College Teaching and Learning (pp. 9-17). Jacksonville, FL: Florida Community College at Jacksonville.

[5] Başal, A. (2015). The implementation of a flipped classroom in foreign language teaching. Turkish Online Journal of Distance Education, 16(4), 28-37.

[6] Bhagat, K. K., Chang, C. N., \& Chang, C. Y. (2016). The impact of the flipped classroom on mathematics concept learning in high school. Educational Technology \& Society, 19(3), 134-142.

[7] Bishop, J., \& Verleger, M. A. (2013). The Flipped Classroom: A Survey of the Research. In 2013 ASEE Annual Conference \& Exposition. Atlanta, Georgia.

[8] Braun, V., \& Clarke, V. (2006). Using thematic analysis in psychology. Qualitative Research in Psychology, 3(2), 77-101.

[9] Bui, T. M. T. (2016). Applying flipped learning in the Vietnamese EFL context: A theoretical discussion of the benefits and challenges. Journal of Military Foreign Language Studies, 3, 33-37.

[10] Chao, C. Y., Chen, Y. T., \& Chuang, K. Y. (2015). Exploring students' learning attitude and achievement in flipped learning supported computer aided design curriculum: a study in high school engineering education. Computer Applications in Engineering Education, 23(4), 514-526.

[11] Chen, L. L. (2016). Impacts of flipped classroom in high school health education. Journal of Educational Technology Systems, 44(4), $411-420$.

[12] Creswell, J. (2009). Research design : Qualitative, quantitative, and mixed methods approaches (3rd ed.). Thousand Oaks: Sage Publications.

[13] Doman, E., \& Webb, M. (2015). Benefits of flipping an EFL classroom in Macao. In E. Doman (Ed.), Reframing English education in Asia (pp. 157-176). Salt Lake City, UT: American Academic Press.

[14] El-Bassuony, J. M. (2016). The effectiveness of flipped learning in developing English grammatical performance of underachieving language learners at the secondary stage. International Journal of English Language Teaching, 4(8), 76-102.

[15] Engin, M. (2014). Extending the flipped classroom model: Developing second language writing skills through student-created digital videos. Journal of the Scholarship of Teaching and Learning, 14(5), 12-26. 
[16] He, W., Holton, A., Farkas, G., \& Warschauer, M. (2016). The effects of flipped instruction on out-of-class study time, exam performance, and student perceptions. Learning and Instruction, 45, 61-71.

[17] Hung, H.-T. (2015). Flipping the classroom for English language learners to foster active learning. Computer Assisted Language Learning, 28(1), 81-96.

[18] Lo, C. K., \& Hew, K. F. (2017). A critical review of flipped classroom challenges in K-12 education: Possible solutions and recommendations for... Research and Practice in Technology Enhanced Learning, 12(4), 1-22.

[19] Lopes, A. P., \& Soares, F. (2018). Perception and performance in a flipped Financial Mathematics classroom. The International Journal of Management Education, 16, 105-113.

[20] Mehring, J. (2017). Present research on the flipped classroom and potential tools for the EFL classroom. Computers in the Schools, 33(1), 1-10.

[21] Milman, N. B. (2012). The flipped classroom strategy: What is it and how can it best be used? Distance Learning, 9(3), 85-87.

[22] Missildine, K., Fountain, R., Summers, L., \& Gosselin, K. (2013). Flipping the classroom to improve student performance and satisfaction. Journal of Nursing Education, 52(10), 597-599.

[23] Nguyen, V. L. (2014). The flipped classroom: A model of blended learning. Science Journal - Can Tho University, 34, 56-61.

[24] Prensky, M. (2001). Digital natives, digital immigrants. On the Horizon, 9(5), 1-6.

[25] Simpson, V., \& Richards, E. (2015). Flipping the classroom to teach population health: Increasing the relevance. Nurse Education in Practice, 15(3), 162-167.

[26] Stone, B. B. (2012). Flip your classroom to increase active learning and student engagement. In Proceedings of the 28th Annual Conference on Distance Teaching \& Learning. Madison, WI.

[27] Strayer, J. (2009). Inverting the classroom: A study of the learning environment when an intelligent tutoring system is used to help students learn. Saarbrücken, Germany: VDM.

[28] Strayer, J. (2012). How learning in an inverted classroom influences cooperation, innovation and task orientation. Learn Environ Res, 15. https://doi.org/10.1007/s10984-012-9108-4.

[29] Tran, T. N. (2016). Applying the "flipped classroom model" for teaching a foreign language. Journal of Foreign Language Studies, Ha Noi University, 46, 67-72.

[30] Tran, T. T. Q. (2017). Students' perceptions of flipped model on Facebook for educational purposes. IOSR Journal of Research \& Method in Education, 7(3), 7-14.

[31] Webb, M., \& Doman, E. (2016). Does the flipped classroom lead to increased gains on learning outcomes in ESL/EFL contexts? CATESOL Journal, 28(1), 39-67.

[32] Yang, C. C. R. (2017). An investigation of the use of the "Flipped classroom" pedagogy in secondary English language classrooms. Journal of Information Technology Education: Innovations in Practice, 16, 1-20.

Nguyen Huu Anh Vuong is currently a PhD student at University Malaysia Sabah, Malaysia. He is also a lecturer at University of Foreign Language Studies, the University of Da Nang, Viet Nam, where he teaches EFL courses. He holds an MA in Applied Linguistics (2012 - The University of Queensland, Australia) and a BA in English Language (2005 - University of Foreign Language Studies, the University of Da Nang, Viet Nam). His main areas of interest include CALL, language teaching methodology and EFL teacher development.

Choon Keong Tan (PhD) is an Associate Professor, Faculty of Psychology and Education, Universiti Malaysia Sabah, Sabah, Malaysia. His main interest in research is on the use of ICT to improve the creative potentials of undergraduates and school children. He has published a number of papers on creativity, e-learning and multimedia in higher education.

Kean Wah Lee (PhD) is an Associate Professor, School of Education, Faculty of Arts and Social Sciences, The University of Nottingham Malaysia Campus, Malaysia. His research interests include CALL, teacher professional development, language teacher learning, language teaching methodology, and language testing \& assessment. 